University of Louisville

ThinkIR: The University of Louisville's Institutional Repository

College of Arts \& Sciences Senior Honors

Theses

College of Arts \& Sciences

$5-2017$

\title{
Making sex work for the state : the policing of sex work in the United States.
}

Madeline A Clabough

University of Louisville

Follow this and additional works at: https://ir.library.louisville.edu/honors

Part of the Bioethics and Medical Ethics Commons, Criminal Law Commons, Ethics and Political Philosophy Commons, Feminist Philosophy Commons, Medical Humanities Commons, Other Feminist, Gender, and Sexuality Studies Commons, Other Psychiatry and Psychology Commons, Public Health Education and Promotion Commons, Women's Health Commons, and the Women's Studies Commons

\section{Recommended Citation}

Clabough, Madeline A, "Making sex work for the state : the policing of sex work in the United States." (2017). College of Arts \& Sciences Senior Honors Theses. Paper 133.

http://doi.org/10.18297/honors/133

This Senior Honors Thesis is brought to you for free and open access by the College of Arts \& Sciences at ThinkIR: The University of Louisville's Institutional Repository. It has been accepted for inclusion in College of Arts \& Sciences Senior Honors Theses by an authorized administrator of ThinkIR: The University of Louisville's Institutional Repository. This title appears here courtesy of the author, who has retained all other copyrights. For more information, please contact thinkir@louisville.edu. 
Making Sex Work for the State: The Regulation of Sex Work in the United States

By

Maddie Clabough

Submitted in partial fulfillment of the requirements

for Graduation summa cum laude

and

for Graduation with Honors from the Department of Political Science

University of Louisville 


\section{Abstract:}

This thesis analyzes the ways that sex work is regulated within the United States, and analyze the ways that regulation is shaped by contemporary feminist discourse. To do so, it analyzes the ways in which sex workers have been and pathologized since the 19th century, and address the ways that these conceptualizations have been incorporated into the legal regulation of sex workers. Finally, this thesis will look to contemporary practices in the state regulation of sex workers, and argue that the relationship between neoliberalism, the carceral state, and what has come to be termed "carceral feminism" operate in conjunction to expand the regulatory capacity of the state. To ground these claims, this thesis applies critical feminist methodology to medical and psychiatric discourses, and the influence that those disciplines have had on legal conceptualizations and regulation of sex workers. This thesis concludes that carceral feminist ideology is functioning to expand the state regulation of sex workers, and that this influence is made possible by the context of neoliberal governance and the carceral state in which carceral feminist logics are operating.

\section{Lay Summary:}

The purpose of this thesis is to analyze the ways that sex work is regulated within the United States, and analyze the ways that state regulation is shaped by contemporary feminist scholarship and activism. To do so, it analyzes the ways in which sex workers have been and addressed in medicine and psychiatry since the 19th century, and argues that the treatment of sex workers in these disciplines has shaped legal understandings of sex work. Finally, this thesis looks to contemporary practices in the state regulation of sex workers, and argues that the relationship between neoliberalism, the carceral state, and what has 
come to be termed "carceral feminism” operate in conjunction to expand the regulatory capacity of the state.

\section{Introduction:}

In this thesis, I will analyze the regulation of sex workers within United States, and argue that new modes of regulation have emerged since the 1970s. To contextualize this argument, I will describe the ways in which sex workers have been pathologized, medicalized, and legally regulated. I will then look to the relationship between the state, feminist logics, and neoliberal forms of governance, and argue that the contemporary regulation of sex workers has been reconfigured by that relationship. I will argue that careal feminism has influenced the ways in which sex work is understood and regulated by the state since the 1970s, and that its rhetoric and logic continues to influence regulatory practices of the state.

For the purposes of this thesis, the definitions and contextual grounding of key terms will largely be drawn from the work "Sex Trafficking and Sex Work: Definitions, Debates and Dynamics — A Review of Literature" by George, Vindhya, and Ray (2010). The term “sex work” will encompass the system of exchanging sex acts for money within the United States, and "sex workers" will be used to describe individuals who participate directly in the aforementioned practice. This is inclusive to street prostitution, escort services, and brothels--but exclusive to practices of sex trafficking (George et al., 2010). In this literature review, George et al. (2010) outlines a complex history of states and NGOs attempting to discern between "sex work" — which entails a level of agency held by the worker —and "sex-trafficking" - in which the individual is a victim being positioned and forced to participate in sex acts by a third party. ${ }^{1}$ George et al. (2010) asserts that this is is a complex and somewhat subjective

\footnotetext{
${ }^{1}$ The complex issue of agency in sex work is one of continued debate in feminist discourse and ethics. For more on this issue of agency in feminism, see Lacey Sloan and Stephanie Wahab in "Feminist Voices on SexWork:
} 
task that theorists, activists, and lawmakers struggle with when confronted with the question of how to punish those involved in the exchange of sex acts for money.

This thesis is focused on sex work exclusively, and how it is regulated within the United States. There is a vast array of experiences and self understandings represented in the term "sex worker," and its use in this thesis will not be in reference to any one set of experiences or class of individuals. Questions of consent and agency, as well as trauma in the practice of sex work--even amongst those sex workers who choose to pursue sex work--are important and certainly carry implications regarding how sex work ought to be regulated. The purpose of this thesis is not to make any claims regarding the status of these issues or how our current regulatory system affects them. Rather, the purpose of this thesis is to analyze these regulatory processes and how they position sex workers in relation to medicine, psychiatry, and the state.

The term "state" will be used in the context of this thesis to reference two entities that are conceptually distinct, but mutually inclusive in their exercise of power in society. There are "states," federal, state, and municipal governments that have legally enumerated powers and--in some cases--cohesive agendas that they are able to pursue through the utilization of their legal power. This thesis will, at points, employ this understanding of the term "state” when addressing various U.S. states, their laws, and some of their police practices pertaining to sex work.

In contrast, "the state" encompases, but is not limited to, the various branches, agencies, and bureaucracies contained within U.S. federal, state, and municipal governments and their laws, as well as military and police forces (Mitchell, 1991, p. 90). “The state," in this way, does not refer exclusively to a particular political system, and it does not stand apart from society or the private sector and its 
functions--its boundaries are porous (Mitchell, 1991, p. 90). Some scholarship in political theory calls for "the state" to be understood a as an amorphous entity that is perceived as having structure and the ability to exert regulatory power over a society (Mitchell, 1991, p. 95). The state is not a defined, cohesive force with a set agenda and mechanisms for carrying out that agenda (Mitchell, 1991, p. 90). Rather, the state is amorphous in its composition, and the sources through which it draws and exerts power are also amorphous in nature--in the case of this thesis those sources include psychiatry and medicine more broadly (Mitchell, 1991, p. 90). In this way, the perception of "the state" as an entity, separate from and governing of society, can be understood as an effect of the structures, institutions, spatial organization, and surveillance and regulatory mechanisms through which it operates and is formed (Mitchell, 1991, p. 95).

In my argument that the regulation of sex workers is expanding the regulatory powers of the state, I refer to this broader conceptualization of the state and its power. Because, however, this broad understanding of the state encompases the powers and behavioirs of governments--characteristic of the more narrow understanding of state defined above--growth in police power or the expansion of legal reach is included in what I am calling "expanded state regulation”. Where I reference specific U.S. states and their laws, I will be employing the understanding of states as entities with enumerated powers and and agendas. Where I discuss the use of medicine or psychiatry by the state, I will be drawing on the conception of the state an entity comprised of various institutions that draws and exerts power through those institutions--though they may not be explicitly or traditionally understood as part of the state governance.

\section{Methodology:}


In order to address how sex workers are pathologized I will use a critical theory framework to analyze the conceptualizations of sex workers in early 19th century psychiatric publications. Specifically, I will analyze the publications' conceptualizations of sex workers as pathological, and assess how these conceptualizations continue to inform contemporary psychiatry, policy formation, and in law enforcement. I will also analyze the aforementioned sources using a feminist psychological philosophy framework, as this lens seeks to address the most basic mechanisms of pathologization as perceived by feminist philosophers.

In order to assess how sex workers are medicalized, I will apply a critical bioethical framework to analyze the policies and rhetoric used within the field of public health on the issue sex work. I will use this framework to discern how those factors shaped how sex workers are conceptualized by medicine, psychiatry, and the law.

In order to answer the question of how sex workers are addressed by legal and carceral structures, I will use a critical legal theory framework to analyze the federal, state, and municipal laws regulating sex work, as well as how those laws are enforced. In order to address how feminist ideologies and neoliberal governance have influenced these forms of regulation, I will used a critical feminist theory framework as well as a comparative method to identify the changes.

\section{Section One: The Medicalization and Pathologization of Sex Workers}

The contemporary state management of sex workers that I later describe relies, in part, upon characterizations of sex workers as pathological. Therefore, I first examine the ways sex workers came to be pathologized and medicalized. I will start by giving an account of medicalization.

Medicalization is a process through which particular nonmedical characteristics, behaviors, and 
issues are made to be medically relevant--worthy of being studied, monitored diagnosed, treated, or prevented due to their actual or perceived influence on individual or public health outcomes (Morgan, 2009, p. 85). Due to their assigned status as medically relevant, these characteristics and behaviors are used as a vehicle for oversight and intervention from various entities--including healthcare practitioners, community groups, police, policy makers, and family members. The types of oversight and intervention that medicalized individuals or characteristics are subject to include overmedicating or performing unnecessary test or procedures, limiting the choices of the patient by not providing relevant information or by denying a line of treatment, and the insistence that the given issue a pathology that can be medically diagnosed, treated, and prevented (Morgan, 2009, p. 86). Insofar as medicalized characteristics are subject to such intervention and oversight, medicalization functions as a form of regulation. It is important to note that these behavior and characteristics were not always considered medically relevant and may have no bearing on the life of the individual displaying them were it not for their medicalized status. As Sadler (2009) defines it, medicalization is a process through which "human problems come to be defined and treated as medical problems.”

Pathologization goes hand in hand with medicalization. It is the process through which some characteristic or behavior comes to be understood as the product of a disease. This disease can be the cause of a bodily or mental illnesses or dysfunction, and is subject to treatment or containment as such (De Block and Ariaens 2013, p. 276) The first organized attempts at in defining and gathering information about mental disorders dates back to the 1840 census (American Psychiatric Association, 2017). Today, the official criteria for identifying a characteristic or behavior as pathological have been standardized in the American Psychiatric Association’s (APA) Diagnostic and Statistical Manual (DSM), which published its first edition in 1952 and its fifth edition in 2013. The DSM has been 
criticized for its inclusion of some behaviors as disorders and the diagnostic criteria it had laid out for others throughout its various publications. For example, the DSM classified homosexuality as a mental disorder from its first publication up until 1973, at which time a series of protests prompted its declassification by the APA (Bayer, 1987). In spite of this declassification, the damage done to those who were--and in some places still are--"treated” through conversion therapy has not faded away (Bayer, 1987; Human Rights Campaign, 2017). The DSM-V’s inclusion of Gender Identity Dysphoria (GID) explicitly pathologizes the experiences and self-understandings of transgender and gender-nonconforming individuals, and situates them within the jurisdiction of psychiatry and medicine. In the case of the aforementioned examples, both have been classified in the DSM as psychological disorders due to a long tradition of pathologizing deviation from sexual and gender norms.

In the same way, understandings of sex workers as pathological are rooted in the pathologization of deviant sexiality. In the early 19th century, psychiatrists adopted the notion that sexual deviance--including participation in sex work--was the result of straying away from the "sexual instinct," or the instinct to engage in sex solely for the purpose of procreation (De Block and Adriaens, 2013, p. 278). This notion shifted sexual deviance out of the realm of biological determinism, where it had been located through a focus on genitalia, and into a context of psychological disorder (De Black and Adriaens, 2013, p. 285). Because sexual deviance was a now framed as a choice between adhering to or straying away from the "sexual instinct," psychiatrists could measure, diagnose, and treat various forms of sexual deviance (De Black and Adriaens, 2013, p. 285). In its mission to identify symptoms and treatments the various sexual disorders they identified, the psychiatric community codified and institutionalized those behaviors as pathological--including participation in sex work.

Furthermore, because participation in sex work has been identified as pathological, it has also 
been identified as something that can and ought to be treated. Psychiatry's claim that sexual deviance is pathological but treatable has created two classes of sexual deviant--one that strays from the norm but seeks treatment, and another that strays from the norm but refuses treatment. In the case of sex workers, those who are willing and able to step away from sex work and overcome their pathology are absolved, and even praised for their bravery (Spongberg, 1997, p. 5). In contrast, sex workers who opt to continue their sex work in the face of other options are not only pathological, but willfully deviant, acting as temptresses and carriers of moral degeneracy (De Black and Adriaens, 2013, p. 285; Spongberg, 1997, p. 5).

This is a paradoxical understanding of sex work as pathological as, by the definition of psychiatric disorder, the sex worker is assumed to be simultaneously out of control of the pathology but is--at the same time--held accountable for its manifestation. In the case of white female sex workers, those who can be identified as victims of sexual violence--those "fallen women"--who are able to recover are differently pathological than those who do not fit and do not seek to fit into a victim class as conceptualized by psychiatry. This includes white women who participate in sex work in the presence of viable alternatives and black women--who have long been characterized in various disciplines as inherently sexually deviant and threatening (Spongberg, 1997, p. 7). This identification of the latter class of sex workers as a threat carries into their legal conceptualization, as well as the ways in which sex workers have come to be medicalized.

Participation in sex work has been medicalized in the U.S. and Great Britain since the 1830s--a time when concern over the spread of venereal disease had escalated to near hysteria in both states (Spongberg, 1997, p. 6). Up to this point, medical research had identified women in general as the source of all venereal disease, as well as moral deficiencies that were associated with such diseases 
(Spongberg, 1997, p. 7). The medical publications of the early 19th century held that the only way that a man could contract a venereal disease was to come into contact with an infected woman (Spongberg, 1997, p. 7) Physicians at this time insisted that any woman, even a virgin, could carry and transmit venereal disease (Spongberg, 1997, p. 5). As the 19th century progressed, however, several factors led to a shift in the relationship between the state, female sexuality, and venereal disease. Rates of venereal disease continued to climb throughout the Industrial Revolution, becoming what would today be called a public health crisis. In addition, the American Civil War simultaneously ushered in a spike in rates of prostitution and a heightened concern for safeguarding the sexual integrity of white women. The demand for plausible explanations and solutions to the spread of venereal disease paired with the drive to construct white female sexuality as pure and in need of protection prompted a shift away from the state and medical field's attempts to identify and regulate all women as sources of venereal disease (Spongberg, 1997, p. 7).

Instead, the medical community narrowed its focus to a class of women who had long been understood as sexually deviant and morally degenerate--a group that could easily be identified and targeted for medical regulation: prostitutes (Spongberg, 1997, p.7). With balck women already depicted as sexually deviant and threatening to white sexuality, the goal became safeguarding white sexuality from threats within white America (Spongberg, 1997, p.7). Identifying white prostitutes, not in a way that was exclusive to black prostitutes but rather to other white women, as the source of venereal disease was politically useful--it provided public officials with a clear answer as to how they could address the spread of these diseases and it reinforced an ideal of pure white female sexuality. With the prostitute identified as the source of the problem, the solution was to identify and treat the prostitute (Spongberg, 1997, p.8). 
The stability and perceived validity of this rhetoric was bolstered by the medical discourse of the time, which set about the work of studying prostitutes as unique subjects (Spongberg, 1997, p. 8). As the 19th century progressed, there was an upsurge in medical research that sought to determine not whether prostitutes were different from the general population, but exactly how prostitutes differed physiologically and psychologically from other women (Spongberg, 1997, p. 8). Already established as sexual deviants and symbols of excessive female sexuality, prostitutes came to be associated with other behaviors that indicated psychological pathology--including addiction and homosexuality (Spongberg, 1997, p 6). Black women, again, were already assumed to be physiologically different, and research on black sex workers reinforced views of them as sexually deviant and degenerate (Spongberg, 1997, p. 8). Physiologically, prostitutes were claimed to display differences in sexual function--specifically pertaining to menstrual cycles--and the size and structure of their genitalia were deemed abnormal (Spongberg, 1997, p. 8). Medical publications warned the general public about the unnaturally and insidiously "sturdy” constitution of prostitutes' bodies, claiming that this constitution allowed for sex workers to be unaffected by venereal diseases, and therefore present no symptoms or other indications of a risk of transmission (Spongberg, 1997, p. 7).

As the 19th century progressed, medical and psychiatric researchers continued to separate prostitutes from the general population of white women by identifying virtually all aspects of their physiology and psychology as pathological. In doing so, medical and psychiatric discourse in the 19th century disassembled the bodies of sex workers, stripped them of their human qualities, and reconfigured them as sites of physical and mental pathologies.

The turn of the 20th century brought with it the rise of public health in America and eugenics movements. Both movements reinforced and were reinforced by the medicalized status of sex workers. 
In terms of eugenics movements, the already established biological inferiority of sex workers and their status as a health risk to the general population were easy to take up and use as justification for the forced sterilization of prostitutes (Schantz, 2007, p. 146). Eugenicists pointed to prostitutes as one of the "undesirable" classes of people whose genetic proliferation would bring about social degradation (Schantz, 2007, p. 146). The established medicalized understanding of sex workers as diseased added credence to the claims of eugenicists, and eugenicists' focus on sex workers as genetically inferior solidified their status as pathological (Spongberg, 1997, p. 8).

The medicalized status of sex workers as carriers of venereal disease and their pathological deviance from the sexual instinct were also taken up and reinforced in the public health rhetoric of the early 20th century. In the third issue of the still running American Journal of Public Health, J. H. Landis (1913) wrote an article entitled “The Social Evil in Relation to the Health Problem” (p. 45). Landis (1913) wrote that "sexual intercourse is a response to primal instinct," and that "its promiscuous gratification creates the social evil with its attendant health problem” (p. 45). The "attendant health problem” to which Landis (1913) is referring is venereal disease-specifically syphilis (p. 45). Landis (1913) goes on to write that "treating syphilis or gonorrhea has about as much influence in getting to the base of the evil as would the snipping off of a few leaves have in cutting down a forest” (p. 45). Landis (1913) spends the next several pages of his article discussing the varied attempts at stopping men from seeking out prostitutes, the ostensible source of all venereal diseases (p. 45-47). Finally, Landis (1913) reveals his solution to the proliferation of the social evil: "eliminate the diseased woman” (p. 47). By Landis' (1913) account, the prostitute was the disease, the source of pathology (p. 47). Furthermore, Landis (1913) believed that "the health problem created by the social evil should receive the same careful attention from the medical profession that is accorded other infectious disease problems (p. 47). 
Landis’ (1913) ability to conflate sex workers and venereal disease was reliant on the fact that sex workers had been remade as the subjects of medical studies--studies that pinpointed them as the root of venereal disease by virtue of their participation in sex work. Furthermore, as is displayed in Landis' (1913) article, the diseased status is so strongly tied to participation in sex work that the only way to treat the disease is to "eliminate the diseased woman” (p. 47). By this logic, the disease in inextricable from the practice of sex work--sex work and the treatment/curing of venereal disease cannot coexist, but if you remove the sex work you can treat the disease. This is a medicalized account of sex work in that it makes disease an essential component of sex work. These inextricable ties between sex work and disease persisted throughout the 20th century, and made themselves evident in public health rhetoric regarding the AIDS Crisis of the 1980s.

The AIDS crisis of the 1980s is remembered by queer communities, in part, as an era in which being queer and being a public health threat were synonymous. Because the disease initially presented almost exclusively amongst gay men and there was no knowledge as to how the disease was transmitted, AIDS was initially identified as a gay man’s disease. When cases of AIDS emerged amongst women and infants, panic over transmission set in and gay men were identified as threats to public health. This status as a threat was used to simultaneously justify both the medical abuse and neglect of white queer identified individuals, people of color, and queer people of color. The explosion of public obsession and terror surrounding sexuality—particularly what could be read as promiscuous sexualities — created a political climate in which the medicalization of sex work could flourish right alongside that of queerness.

In 1988, the American Journal of Public Health published the article "Prostitutes and AIDS: A Health Department Priority?” (Rosenberg et al., 1988, p. 418). The article starts with the assertion 
that "prostitutes are considered [by the Health Department] to be a reservoir for certain sexually transmitted diseases” (Rosenberg et al., p 418). With that established, the question the article addressed was whether or not the Health Department should target prostitutes for testing the treatment, as they were already considered an "at risk group” (Rosenberg et al., 1988, p. 418). The study described in the article found that intravenous drug use almost completely overshadowed sexual behavior as a risk factor, and found that sex workers who did not use intravenous drugs had the same risk of exposure to AIDS as other women multiple sexual partners (Rosenberg et al., 1988, p. 420).

A 1989 letter to the editor in the American Journal of Public Health, addressed yet another article tying the spread of HIV/AIDS to sex workers (Leonard et al., 1989, p. 1310). Leonard et al. (1989) calls for an increase in public awareness about the risks of engaging in unprotected oral sex with prostitutes, as this is a site of HIV transmission (p. 1310). While the authors of this Letter to the Editor are not wrong about the potential for transmission through oral sex, the explicit focus on sex workers implies that this risk is specific to sex workers, and fails to indicate that individuals who do not engage with sex work are subject to this risk as well.

In “The Movement to Criminalize Sex Work in the United States,” Ronald Weitzer (2010) gives an account of international AIDS advocacy that demonstrates further how effectively connections between sex workers and AIDS were formed and deployed. Weitzer (2010) argues that the treatment of sex work as a health problem was supported at the international scale with the 2003 Global AIDS Act. The Act declares that any international organization that receives funding to ameliorate the impact of AIDS is obligated to "have a policy explicitly opposing prostitution and sex trafficking" (p. 74). If the organization does not have such a policy, it is not eligible to receive funding. The implication of this policy is that AIDS and sex work are intimately related — that an organization cannot work to mitigate 
the impact of AIDS while supporting sex workers. The implication is that sex workers play a role in the spread of AIDS - that they are the carriers of disease and the site of a global health crisis. In order to stop the spread of AIDS, one must stop the practice of sex work.

Both the 1988 and 1989 pieces from the American Journal of Public Health and the Weitzer piece reference the same medicalized understanding of sex workers that emerged in the 19th century--an understanding that sex workers are "reservoirs of...diseases” (Rosenberg et al., 1988, p. 418). They are diseased or carriers of disease by virtue of their participation in sex work. The only variation is in what diseases they are assumed to be carrying--or at least which one is the most urgent health priority. In the 19th and early 20th century the diseases were gonorrhea and syphilis. After 1980 they were HIV and AIDS.

The conceptualizations of sex workers that emerged in 19th century medical and psychiatric discourse function to create the sex worker as a medicalized and pathological subject. Those designations have persisted and carry implications that extend far beyond medicine, psychiatry, and public health. Therefore, in the following section I will analyze the ways the medicalization of sex workers has manifested in the legal system.

\section{Section Two: Legal Regulation and the Influences of Medicalization}

Having established how sex workers are medicalized, I will now address how these conceptualization have been taken up in legal discourse to reinforce policing practices and the criminalization of sex workers by courts. Discussion of the influence of the pathologization of sex workers on their legal regulation will be in the third section. 
First, it is important to note significant role that medical and psychiatric experts have had in crafting the legal definitions of terms relating to sex work and countless other topics that have been the focus of legal discourse (Spongberg, 1997, p. 5). For example, as stated in the previous section of this thesis, the viability of political identifications of sex workers as the source of venereal disease were reliant upon support for those claims from medical and psychiatric experts. In this way, our legal understandings of sex work already reflect, in part, our medical and psychiatric understandings. With that established, I will start by giving a brief account of the laws that explicitly regulate the practice of sex work in the United States, and provide a short description of the most common forms of sex work practiced today. I will then demonstrate the ways that the medicalization of sex workers has been taken up in the U.S. legal system.

With the exception of eleven counties in Nevada, sex work is illegal at both the federal and state level. The only form of sex work that the U.S. federal government is involved with directly is sex work performed or facilitated by “aliens” who are in or have expressed intention to enter the United States (“US Federal and State Prostitution Laws,” 2016). There are also numerous federal laws criminalizing “prostitution near military and naval establishments” (“US Federal and State Prostitution Laws,” 2016). Immigrants' ability to stay in the United States is put in immediate jeopardy when they are found by authorities to be participating in sex work in any capacity. According to U.S. Code Title VIII, "Any alien who-- (i) is coming to the United States solely, principally, or incidentally to engage in prostitution, or has engaged in prostitution within ten years of the date of application for a visa, admission, or adjustment of status...is inadmissible” (“US State and Federal Prostitution Laws,” 2016).

That established, state laws are the primary medium for formally criminalizing and legally regulating sex work in the United States. States vary considerably in the penalties they impose for 
participation in the selling of sex, and the punishment varies based on the role an individual plays in that process. These roles are most commonly classified as "prostitute”, “customer”, “pimp”, and "brothel owners"-and punishments for all classes range from fines to felony charges and jail time ("US Federal and State Prostitution Laws,” 2016). The most common penalty for first time offenders classified as prostitutes or customers is a misdemeanor charge, a fine ranging by state from $\$ 100$ to $\$ 10,000$ dollars, and potential prison time that in most states falls at or under a year, although first-time offenders for both groups can up to two years in Iowa (“US Federal and State Prostitution Laws,” 2016). As the number of offenses reaches three and above prostitutes and customers can face felony charges and up to five years in prison (“US Federal and State Prostitution Laws,” 2016).

The sex work market is itself complex, with different methods and practices being used to carry out the buying and selling of sex acts. "Street prostitution” and prostitution carried out in "private venues” are the two primary vehicles for sex work in the United States (Human Rights Watch, 2012; “US Federal and State Prostitution Laws,” 2016). Street prostitution is the walking of public areas for the purpose of solicitation. Private venue prostitution typically grants more control to the sex worker, be they operating as an individual or as a part of a group using a fixed location—such as a parlor—as a front for selling sex (Sanders et al., 2007). The parlor structure has, in some cases, allowed for the semi-organization of involved sex workers and other "employees” such as a receptionist (Sanders et al., 2007). That level of organization has been found to enhance the security of the sex workers operating out of the parlor through increased screening of customers by the receptionist and a feeling of professionalism that has been found to increase the likelihood of customers abiding by set boundaries (Sanders et al., 2007).

Another feature of private venue sex work is that it positions the sex worker out of the public 
eye, and therefore reduces the chance that they will be targeted for legal regulation through vagrancy and stop-and-frisk ordinances. Historically, vagrancy laws have been used to as a means to arrest or remove from publics spaces classes of individuals that were deemed suspect or altogether undesirable (Hobson, 1987, p. 25). Sex workers, by virtue of their sexual deviance and display of that deviance in public spaces, have been the subjects of such laws since their inception (Hobson, 1987, p. 25). Vagrancy laws have provided legal grounds for police to approach and question sex workers, or those they think are sex workers, in order to produce the information needed to arrest, forcibly relocate, or ban the individual in question from public spaces (Hobson, 1987, p. 26). Throughout the 20th century many vagrancy laws increasingly fell out of favor with courts because they were either too broad or too explicit in their targeting of specific classes of people (Hobson, 1987, p. 26). The regulatory function of vagrancy laws has not disappeared along with the laws’ use. Rather, laws addressing loitering have come to serve as pretext for police to approach and question those they suspect of soliciting or prostitution (Hobson, 1987, p. 26). In some states and municipalities, loitering laws have been adopted that target sex workers specifically, identify an act of "loiter with intent to commit prostitution" (California Penal Code 653.22(a), 2017). If an individual is approached by police using this law, possession of a condom can be used as evidence to convict them of prostitution related changes (Human Rights Watch, 2012).

Recent studies conducted by groups including Human Rights Watch, the Sex Worker Project, and the World Health Organization on police practices regarding sex work reveal that it is common for police to use the possession of condoms as evidence in cases to convict individuals of prostitution related charges (Human Rights Watch, 2012; Amin, 2005). This practice has been researched and documented in detail by Human Rights Watch (2012) in U.S. several major U.S. cities, including New 
York, Los Angeles, and San Francisco, and Washington D.C.. The goal of their research was to determine the impact that using condoms as evidence in criminal court has on public health. Specifically, the researchers were interested in how the risk of potential legal ramifications impacted the likelihood that sex workers and queer youth would carry and use condoms (Human Rights Watch, 2012). Through research on the various cases in which condoms have been used as evidence by police and interviews with those who had either directly experienced or were aware of this policing practice, Human Rights Watch (2012) found that "some members of the groups most at risk of [HIV] infection — sex workers, transgender women, and lesbian, gay, bisexual, and transgender (LGBT) youth—fear carrying condoms to the point where they carry only a few, or none at all and...engage in sex without protection as a result” (Human Rights Watch, 2012).

Given the established medicalized status of sex workers as carriers of venereal diseases, this police practice would seem counterproductive in achieving a long-standing public health goal of reducing the transmission of venereal disease from sex workers to "the general population," implying that this view has not been taken up within legal regulation. However, in the context of "hold and treat" ordinances, the taking up of medicalized conceptions of sex workers by the police and courts renders arrest--even at the expense of condom use--a productive method for limiting the spread of venereal disease.

“Hold and treat” laws and ordinances allow police officers to arrest and detain sex workers until they consent to testing and treatment for venereal disease (Code 1950, § 735.1). These laws and ordinances target those who can be "reasonably suspected" of having a venereal disease (Code 1950, § 735.1). Some only require testing for HIV and AIDS--as is the case in California's Penal Code--while others call for a complete screening--as is the case in a Denver ordinance that has been on the books 
since 1950 (Code 1950, § 735.1, 2016; Curran, 1975). This ordinance demonstrates how courts and police have taken up and applied a medicalized conception of sex workers as carriers of venereal disease.

An analysis of the court case Reynolds v. McNicholas was published by the American Journal of Public Health in 1975 (Curran). In what Curran (1975) proudly called a "real old-fashioned public health law decision," the U.S. Court of Appeals $10^{\text {th }}$ Circuit upheld the constitutionality of a City of Denver Ordinance that allowed for Ms. Reynolds - a sex worker - to be detained after arrest until she agreed to take a dose of oral penicillin (p.180). The penicillin was ordered as treatment for an assumed venereal disease, not one that has a positive test associated with it (p. 180). The court claimed several grounds for making this decision. Because Ms. Reynolds had an arrest history for prostitution and had previously complied on two occasions with orders for examination at the Department of Health and Hospitals, she qualified for the "hold and treat" ordinance that targeted those "reasonably suspected" of having venereal diseases (Curran, 1975, p. 180).

There are several aspects of this case that are demonstrative of the adoption of medicalized understandings of sex work in its legal regulation. First, on the two occasions that Ms. Reynolds had been ordered to undergo examination and potential treatment at the Department of Health and Hospitals, this order had been given by police as an alternative to arrest (Curran, 1975, p. 180). The fact that police, in this specific case, viewed medical regulation as a viable substitute for legal regulation demonstrates an understanding of sex workers as medical subjects. Furthermore, by ordering Ms. Reynolds to seek medical care, the police officers--in that moment--extended their jurisdiction beyond issues of the law and into issues of medicine. In doing so, the police officers, without the backing of a court or the knowledge of an existing disease, assumed the authority to dictate when and where Ms. 
Reynolds would undergo medical examination. With arrest and the near certainty of conviction as the alternative, Ms. Reynolds had virtually no means to resist the officer’s exercise of medical authority. The first time she complied with the order, Ms. Reynolds was diagnosed and treated for gonorrhea (Curran, 1975, p. 180). The second time she complied with the order for examination, she was found to be completely free of any venereal disease and was released without treatment (Curran, 1975, p. 180). Despite the results of the more recent ordered examination and the fact that she was coerced into undergoing both examinations, the fact that Ms. Reynolds has consented to the examinations was part of the justification used by the court in support of the application of the "detain and treat” ordinance Ms. Reynolds was subject to. A medicalized view of Ms. Reynolds as a sex worker prompted the officers to order her to seek medical treatment, and her compliance in doing so (although coerced) was used by the court to reinforce that medicalized conceptualization and justify forced medical treatment.

In this case, it was Ms. Reynold's status as a prostitute that situated her in the realm of “reasonable suspicion” as laid out by the Denver ordinance, and was used to justify the suspension of her constitutional rights and forced medical treatment. The medicalized status of sex work as synonymous with venereal disease served as the authority and rationale in the expanded legal regulation of Ms. Reynolds and her body.

The incorporation of a medicalized view of sex work into legal discourse also shapes laws that mandate STI testing for those who are arrested or convicted of sex work. Within the United States, there are roughly twenty five laws that mandate testing, medical treatment, and felony charges if certain infections are detected (Koster and Dunn, p. 1-2). Judges in cases in which the detection of an STI is not legally relevant — cases that do not involve positive HIV tests—-have still used positive STI tests to 
justify longer sentences, higher fines, and invasive and unwelcomed medical intervention (Koster and Dunn, p. 2-3).

The use of mandatory testing laws also dates back to the AIDS crisis and shows how profoundly individuals were able to be legally regulated through the taking up of a medicalization of sex work. In On the Issue Magazine, Carol Leigh (1988)—a feminist prostitute and activist—gives an account of a woman in California who, upon testing positive for HIV, was asked to wear a mask throughout her trial to prevent the spread of AIDS (p. 1). When challenged on the necessity of the mask, the judge argued that "he did not have time to research how HIV is transferred" (Leigh, 1988, p. 1). He held that her status as a health risk — as an HIV-positive prostitute-justified his order that she wear the mask while in his courtroom (Leigh, 1988, p. 1). Leigh (1988) goes on to argue that "mandatory HIV testing for prostitutes scapegoats us as easy targets...manipulating our fate for the purpose of warning the general public" (p. 3). Leigh’s (1988) understanding of the "fate” of prostitutes as sources of pathology in the context of the AIDS crisis is demonstrative of the medicalized nature of sex workers. In this case, medicalized understandings of sex workers have been applied in legal regulation to control sex workers and perpetuate an understanding of sex workers that is rooted in pathology.

\section{Section Three: Developments in Regulation Since the 1970s}

Having established how sex workers are pathologized and medicalized, and how those conceptions have influenced the ways sex work is legally regulated, I will now address how the state's regulation of sex work has changed since the 1970s . Specifically, I will address how the rise of neoliberal forms of governance, the carceral state, and the influence of feminist logics and the 
pathologization of sex work have reconfigured state regulation of sex workers. In order to do so, I will first define neoliberalism, the carceral state, and carceral feminism. I will then demonstrate how these phenomena have worked together to change the ways that sex workers are legally regulated in the United States, namely by making sex work a vehicle for the expansion of the carceral state.

I will start by giving an account of neoliberalism. Wendy Brown (2015) gives an account of neoliberalism as a complex phenomena that has no stable definition, but can be understood as a shift in political and economic policies that began in the 1970s. These changes included the reduction of government spending on social programs, movement towards privatization, emphasis on finance capital, and the deployment of rhetoric that emphasized individual economic freedom and responsibility (Brown, 2015). Bernstein (2012) lays out these neoliberal influences on the politics of sex work through discussing the use of criminalization under neoliberal policies, and the disparate racial effects of these policies. Specifically, Bernstein (2012) argues that criminalization is used as a form of social control that helped instill a sense of middle-class security that had been diminished with the reduction of the welfare state--which had previously operated both as a support system for middle class families and as an apparatus of containment for what were now described as degenerate or dangerous classes of people through the moralization of market participation (Bernstein, 2012). Politicians--such as Ronald Reagan--deployed highly racialized images of economic dependency on the state, and used this tactic--among others--to justify the economic restructuring of the United States through privatization, deregulation, and the dismantling of social services programs (Bumiller, 2008; Brown, 2015). The reduction in the support of the government created an atmosphere of vulnerability and risk, particularly among white, middle-class Americans (Bernstein, 2012). Specifically, white, middleclass women developed fears of sexual violence due to a multiplicity of factors that reinforce their sexual desirability 
and vulnerability (Bernstein, 2010). In order to address these anxieties, criminalization and incarceration boomed as a means of social control, particularly of communities of color, in what scholarship dating back to the 1990s has termed the "carceral state".

The term "carceral state" references the expansive system of prisons, policing, and mass incarceration within the United States, and the status of that system as a primary form of governance and regulation (Hernandez, Muhammad, and Thompson, 2015). The roots of the American carceral state are racial, and date back to the passage of the Thirteenth Amendment (Hernandez et al., 2015). After chattel slavery was abolished, Black Codes and prisons emerged as a means of subjugating and regulating black bodies (Hernandez et al., 2015). The Convict-Lease system--in which black men were criminalized, incarcerated, and their labor was used as capital--was highly lucrative for white businesses, and essential to industrialization. These laws and the Convict-Lease system established a network policing and prisons capable of mass incarceration, and laid the groundwork for the rise of the carceral state (Hernandez et al., 2015).

The 1970s marked the beginning of a boom in the size and reach of the U.S. carceral system--and this growth has shown no signs of stopping (Hernandez et al., 2015). Numerous political, social, and economic forces have been identified as contributing to the rise of the carceral state, and there is no single, agreed upon narrative. It can be explained, in part, by the political shifts that occurred throughout this period, including President Lyndon Johnson's declaration of the "war against crime” in 1965, and President Nixon’s “war on drugs” in 1971 (Gottschalk, 2011). Both of these declarations were paired with changes in penal codes that expanded police power, reclassified offenses as felonies, created harsher sentences, and reduced the rights of those incarcerated (Gottschalk, 2011). They also generated the perception that crime was a constant, pervasive threat to the public, rationalizing the 
growth as necessary (Gottschalk, 2011). This political rhetoric was carried forward by the Reagan, Bush, and Clinton administrations, and the shrinking of government support through neoliberal reforms generated a sense of risk and insecurity that the increase in policing mitigated amongst white Americans (Hernandez et al., 2015).

Today, an estimated 2 million people are currently held in U.S. prisons, immigration detention centers, and jails (Hernandez et al., 2015). Analysis of the racial distribution of those 2 million being held reveals that black men and women, and Latino individuals are incarcerated at rates that are disproportionately high in comparison to the size of their population within the U.S. (Bumiller, 2008, Flaherty, 2010; Hernández et al, 2015). Additionally, roughly 65 million people within the U.S. have a criminal record (Hernandez et al., 2015).

The size of the carceral system and the influence it has on the economy--as a site of countless jobs and investments--has generated a financial incentive to maintain and grow the prison population. Incorporating sex work into criminal law casts a wider net for that prison population, aligning the continued criminalization of sex work with neoliberal market interests in finance capital. Additionally, the vastness of the carceral state and the role it plays in creating a hyper-criminalized view of society bolster the influence that carceral feminism has in making sex work a vehicle for the expansion of the carceral state.

I will now offer a more detailed account carceral feminism. Discourse surrounding sex work almost exclusively depicts the sex worker as female and the buyer as male, despite the fact that—while the female/male dyad is the most common (or, at least, the most studied) — there exists a multiplicity of gender and sexual orientation dynamics in the sex work industry, as asserted by Maher, Pickering, and Gerard (2012). This a narrow characterization carries with it the historically oppressive dynamic 
involving the male domination and possession of the female body. Some feminists argue that this domination is reinforced by a man's ability to purchase the use of a woman's body, and that it renders women's bodies as objects to be exploited for men's pleasure (Sanders, 2013). This view of sex work as inherently oppressive to women is essential to some current feminist arguments that sex work of any kind is sexual exploitation — by some accounts even rape (Sanders, 2013). This characterization of sex work is used to assert that it is necessary to abolish sex work in order to protect, advance, and liberate women (Sanders, 2013).

According to Elizabeth Bernstein (2012) in her article, Carceral Politics as Gender Justice? The "traffic in Women" and Neoliberal Circuits of Crime, Sex, and Rights, the use of this argument signifies an important shift in the purpose of some feminist movements--a shift that ushered in what has come to be understood as carceral feminism. The term "carceral feminism” developed in recent scholarship to describe a trend that emerged roughly in the 1970s with the Victims Rights Movement of some feminist groups calling for harsher laws and increased policing of sexual violence against women (Bumiller, 2008, p.4). The effect of these demands has been the growth of the carceral state that, in part, is informed by carceral feminist logics and rhetoric (Bernstein, 2012).

Bernstein (2012) argues that the purpose of feminism within the United States ought to be women's liberation through demanding economic, political, domestic, and sexual forms of freedom and agency previously withheld by a patriarchal state. Using that ideological history as a backdrop, Bernstein (2012) argues that current mainstream feminist groups are using the defense and protection of women from sexual violence as a means to incorporate them into the carceral system. Bernstein (2012) claims that this shift is largely due to the influence of neoliberalism on white, upper-middle-class feminism, and that the product of that influence is a feminist vehicle for the spreading of a carceral state out of fear of 
sexual violence against women. Bernstein also argues that this anxiety paired with mainstream white, middle-class feminism's adoption of rhetoric of “family values” concerning sexuality has culminated in a practice of has been termed carceral feminism (Bernstein, 2012). By Bernstein’s (2012) account, carceral feminism acts to criminalize and incarcerate those who commit violence-particularly sexual violence-against women. Given the clearly disparate impact of the carceral system on communities of color, carceral feminism is largely understood a white feminism, as it fails to take into account the reality of race in the carceral state (Bumiller, 2008, p. 27).

The argument that female sex workers are sexually exploited--victims of rape by some accounts--situates sex work within the rise of carceral feminism. Bumiller (2008) pinpoints the 1960s as the period in which feminist groups--particularly radical feminists--began to organize around the issue of sexual violence against women, demanding that the state "take responsibility” for this issue (p. 2). By their account, taking responsibility meant increasing the reach and force of the criminal justice system to better target the perpetrators of violence against women (Bumiller, 2008, p.2). Since, sex work has been consistently identified in feminist and legal discourse as a form of sexual violence and exploitation that ought to be addressed (Sloan and Wahab, 2000, p. 461-462).

Carceral feminists’ arguments and conceptualizations surrounding sex work are not new to American feminist discourse. Feminist organizations dating back to the early 19th century viewed sex work as a manifestation and proliferating force of gender inequality (Hobson, 1987, p. 65). The New England Female Moral Reform Society, which was founded in 1824, was one such group (Hobson, 1987, p. 65). Like carceral feminists, The Society argued that exploitation, specifically men’s exploitation of women, was an inherent characteristic of sex work, and that the focus of legal regulation on sex workers alone functioned to criminalize women at disproportionate rates and reinforce the 
socially disadvantaged status (Hobson, 1987, p. 66). In its various publications of its magazine, The Virtue, The Society contended that the only way to eliminate these gender inequalities and protect women from sexual violence and exploitation at the hands of men was to abolish sex work (Hobson, 1987, p. 67). To achieve this end, the organization advocated for the expanded policing of sex workers, brothel owners, and solicitors (Hobson, 1987, p. 65-66). The Society was not the only active feminist group during its time making these arguments (Hobson, 1987, p.67). The work of these organizations resulted in the passage of a few local ordinances that criminalized "seduction"--which was the term used at the time to describe male solicitation (Hobson, 1987, p. 67). However, these movements not only failed to abolish sex work, but they also failed to popularize their arguments, and significantly influence the ways sex work was conceptualized and regulated by the state ( Hobson, 1987, p. 67-68).

While The Society's arguments and ways of conceptualizing sex workers may have failed to gain traction in 19th century, I argue that the presence of neoliberal forms of governance and the rise of the carceral state facilitated carceral feminism's success in influencing discourse through the deployment of those same arguments and conceptualizations.

One of the paradoxes of neoliberalism is that the advocates for state deregulation--particularly of the economy--and the shrinking of the government in the lives of individuals, while simultaneously using an increase in policing and incarceration to bolster feelings of public security--mainly for white communities (Bernstein, 2013; Bumiller, 2008).This particularly applies in the case of sexual violence against women, providing a foothold for carceral feminist calls for the increased criminalization of the men who solicit sex work (Bernstein, 2012; Bumiller, 2008). Unlike the demands made by The Society in the 19th century, demands by carceral feminists for the increased criminalization of men who solicit are broadly influencing policing practices. This influence is channeled through lobbying--as in the case if 
the 1994 Violence Against Women Act for example--as well as through demonstrations and other efforts to raise public awareness surrounding violence against women. The ability of carceral feminist logics to gain traction on a broader scale than those of The Society is due to the political context of the carceral state and neoliberal forms of governance, and the influence of carceral feminist activism can be seen in the ways it has expanded the carceral system to widen the net for those who solicit sex workers. Solicitation is illegal in all states, again, with the exception of the counties in Nevada in which one can legally go to a brothel and pay for sex (“US Federal and State Prostitution Laws,” 2016). However, numerous cities and states in the U.S. have taken up policing initiatives that specifically target “Johns," a term the refers to men who solicit sex work (Brown, E., 2014). These include New York, Boston, St. Louis, and New Jersey, California, Cincinnati, Seattle, Chicago, and Phoenix (Alter, 2016; Brown, E., 2014). The asserted goals of these programs and initiatives varies, but a common theme is the idea that these policies somehow shift the burden of sex workers to their clients while helping to cut down on prostitution, sex trafficking, and sexual violence (Alter, 2016). All have the expressed goal of ending prostitution (Alter, 2016). The spread of these programs (all within the last fifteen years), their application, and their expressed goals reflect logics and arguments put forth in carceral feminism. Whether directly or indirectly, carceral feminism has influenced policies regulating sex work, and the effect of these policies is that more people are incorporated into the carceral system--both sex workers and Johns. Policies for targeting Johns are not the only aspects of legal regulation of sex workers that bear the mark of carceral feminism.

In addition to cracking down on Johns, New York City has doubled the number of officers in its vice enforcement unit since January, 2017 (Whitford, 2017). This expansion of the police force is part of a larger campaign being carried out by the mayor's office and NYPD to curb human trafficking in the 
city (Whitford, 2017). The goal, NYPD Commissioner James O'Neill asserts, will be to 'build trust between victims and police,” and to better identify and help victims of sexual violence--particularly immigrant victims (Whitford, 2017). However, in spite of the asserted intentions of Commissioner O’Neill, the practices of this expanded vice squad have, thus far, only resulted in higher rates of arrest and conviction for prostitution (Whitford, 2017). This is due, in part, to the fact that upon their arrest for solicitation, individuals are asked a series of questions to determine whether or not they are a victim of sexual exploitation (Whitford, 2017). If they are not identified as a victim--which has been the case for dozens of arrested women--they are charged with prostitution (Whitford, 2017). Legal Aid attorney Kate Mogulescu has criticized the new police initiative (Whitford, 2017) Mogulescu is currently representing one woman who was arrested for prostitution, along with five other women, in a sting that the NYPD identified as an attempt to target a trafficking ring (Whitford, 2017). In regards to the human trafficking initiative that was used as the rationale behind this raid, Mogulescu asserts that "the NYPD should not escape scrutiny by using the rhetoric of trafficking, but then continuing to engage in the status quo" (Whitford, 2017).

This case is a prime example of the role carceral feminism has come to play in reconfiguring sex worker's relationship to the state (here represented by NYPD). In this case, the influence of carceral feminism is manifesting in one of two ways, depending on the intentionality of the NYPD. The first potential manifestation is identified in Mogulescu's criticism of the NYPD initiative. Mogulescu implies in her criticism that the NYPD is intentionally deploying a rhetoric of concern for victims of sex trafficking in an effort to mask their true agenda--the increased policing of prostitutes (Mogulescu, 2017). If this implication were true, as it may well be, it would mean that the NYPD--a state entity--has co-opted carceral feminist interests, logics, and rhetorics for the purpose of expanding its regulatory capacity. The 
second possibility for how carceral feminism has influenced the regulatory practices of the NYPD is through its proliferation of the idea that any sex worker could be an unidentified victim of sex trafficking or another form of sexual violence and exploitation. In the face of this possibility, a genuine commitment to helping victims of sexual violence would require the NYPD to round up and sort through sex workers in order to identify the victims amongst them. The implied scope and urgency of this project would render the NYPD’s initiative--with its enlarged vice unit, spike in arrests, and questionnaire for identifying victims--a viable solution. In this way, reconfigurations of sex work by carceral feminism facilitated a new, expanded model of state regulation of sex work. Furthermore, the two sites of influence are not mutually exclusive--the NYPD could have a genuine concern for victims of sexual violence and still use that rhetoric to mask an intentional expansion of the NYPD's regulation of individuals they have already identified as prostitutes. Regardless of whether the NYPD was intentionally deploying carceral feminist logics or simply responding to carceral feminists' demands for the protection of victims of sexual violence, carceral feminism played a role in how the NYPD crafted its most recent approach to the regulation of sex workers.

There is no information on this case regarding what type of direct contact NYPD had with carceral feminists--and direct contact is not necessarily required for the influence to have occurred. Bernstein (2012) names New York City as an site of consistent and highly visible organizing and protest surrounding sexual violence against women--specifically human trafficking. Whether the NYPD spoke to these organizers or some other source when formulating their policies is not stated--but the influence is clear nonetheless in the uptake of human trafficking as a priority in policy making. In this case, the NYPD or feminist groups could have been the active party in directly demanding the changes in policy. In the case of the 1994 Violence Against Women Act, however, the lobbying and organizing efforts of 
carceral feminist groups was key to its passage at the federal level.

The 1994 Violence Against Women Act (VAWA) serves as another case study on how carceral feminists--through direct action and lobbying--have expanded the reach and power of the carceral state (Whittier, 2016, p.791). The VAWA focused issues of sexual and domestic violence against women, including prostitution, and had funneled billions of dollars annually since its passage on increasing policing and prosecution alone (Law, 2011). In addition to this increase in funding, the VAWA enumerates mandatory sentencing, increased pretrial detention, and mandatory HIV testing--first at arrest and then at conviction.

Although this Act has advanced the safety and wellbeing of victims of sexual and domestic violence, these effects are not felt the same along racial and class lines, and sex workers are continually marginalized by this Act as well (Bumiller, 2008; Law, 2011). Already subject to disproportionate policing and incarceration, black men have been affected by this law at higher rates--by population percentage--than white men have (Bumiller, 2008; Law, 2011). For many black women, this law is ineffectual--even dangerous--to call on (Law, 2011). Police continue to either disregard their claims of violence, use the encounter to arrest both the victim and the alleged perpetrator, or enact violence against black women themselves (Law, 2011). For sex workers of all races, reports of sexual violence are consistently disregarded and their calling on police used as a point of arrest or violence that is carried out by police (Law, 2011). The VAWA is another example of how carceral feminist logics have directly influenced the carceral system, and demonstrated that these logics either do not take into account or are not concerned over the disparate impact that the criminal justice system has on communities of color and sex workers. This influence is also clear in the sections that address protections for immigrant women in the VAWA. 
In efforts to make the VAWA more inclusive, it protections have expanded throughout its various legislative renewal processes. One area that has been of concern in the last 15 years is protections for immigrant women--whether they arrived through legal or illegal means (American Immigration Council, 2005). In The Battered Immigrant Women Protection Act of 2000, new pathways to obtaining visas were laid out for women who could identify themselves as victims of sexual or domestic violence, or a range of other criminal activities (American Immigration Council, 2005; VAWA 2000). The criminal activities listed rape, "substantial physical or mental abuse," murder, felonious assault, sex trafficking, torture, and prostitution--among others (American Immigration Council, 2005). The mention of both sex trafficking and prostitution in important to note, in that it situates both as producing a victim. In addition, the Act requires that, in order to obtain the visa, the victim of the crime must be "be helpful, have been helpful, or be likely to be helpful to a federal, state, or local investigation or prosecution of the criminal activity" (American Immigration Council, 2005). In this way, the victim--as conceptualized in this law--is required to incorporate themselves into the expansion of the carceral system if they are to obtain legal protection and a visa. In the case of identified prostitutes, taking up a victim role--whether genuinely or strategically--and targeting their fellow sex workers, customers, or pimps for criminal investigation very well may be the best option made available to them by the VAWA.

A pathologized understanding of sex work is evinced in these efforts to identify and recover victims of sex work so that they can be treated and, in turn, the criminals so that they can be incarcerated. As described in accounts of how sex work was pathologized in the early 19th century and on, not all sex workers are ascribed the same pathology. Insofar as sex work--as sexual deviance--can be identified by psychiatrists it can also be treated. However, the root cause of that pathology, and the 
approach to treating its manifestation through participation in sex work, depends largely on the extent to which the sex worker can be identified as a victim of violence that is willing to be treated. As established, a defining characteristic of a psychiatric disorder is that one cannot help having it--the behavior or characteristic must be out of the control of the afflicted (APA).

Accounts of sex workers as frequently being victims of sexual violence--often in youth--is an example of one of the understandings of sex work rooted in pathology. The findings of various psychiatric and public health research publications argue that many sex workers have experienced trauma that led them to their practice of sex work (Ankesaria and Gentile, 2012; Kurtz, 2005; Marvasti, 2004). These studies argue for a causal relationship between trauma and sex work, depicting sex work as something that cannot be helped and that sex workers would quit sex workers if they were able--an understanding that is in line with definitions of psychiatric disorders as involuntary in the DSM.

Dr. Jamshid Marvasti (2004), for example, includes a section dedicated to prostitution in her book, Psychiatric Treatment of Victims and Survivors of Sexual Trauma (p.34). In this section, Marvasti discusses the research of numerous other psychiatrists on identifying the reasons that women go into sex work. She concludes, in concert with the other mentioned researchers, that taruma--particularly childhood sexual trauma is a primary cause of up to 70 percent of women's engagement in sex work (Marvasti, 2004, p. 34). Marvasti’s (2004) book references and contributes to a growing body of psychiatric literature that aims to understand sex work in terms of trauma and subsequent pathology (Anklesaria and Gentile, 2012; Jung et al., 2008). The normative claims or implications of these pieces is that sex workers who are victims of trauma ought to be understood and 
addressed through psychiatry rather than criminalization.

An example of this trend in public health discourse is the article "Barriers to Health and Social Services for Street-Based Sex Workers,” published by the Journal of Health Care for the Poor and Underserved (Kurtz et al., 2005). This article is one example of how a narrative of sex workers being in need of psychiatric intervention has emerged (Kurtz et al., 2005). Kurtz et al. (2005) employ a sweeping generalization about sex workers in the following analysis of sex workers, delivered in the introduction of their article:

Significant numbers of street-based sex workers have histories of childhood sexual and physical abuse, increasing their susceptibility to mental and emotional problems...Indeed, many of these problems are self-perpetuating....and contribute to mental and physical health problems that require attention.

This public health article argues that many sex workers ought to be understood as victims, rather than criminals, and that programs--particularly policing policies--that address these individuals ought to prioritize identifying the needs of sex workers as victims of violence. This article makes no mention of sex workers who do not have a history of trauma that would "lead them" to engage in sex work. My commentary on these articles and the trends they depict should not be read as a claim that sex workers do not experience trauma, that trauma has no effect in their participation in sex work, or 
that recognizing the reality of sexual violence in sex work is inherently problematic. Rather, I cite these articles to demonstrate that there are two conceptualizations of sex workers as pathological that are at play in how they are regulated. The first, is aligned with contemporary carceral feminist depictions of sex work as inherently violent, and holds that sex workers have been traumatized and are in need of psychiatric rehabilitation. The second pathological understanding is a holdover from the ways sex workers came to be pathologized--and criminalized--through psychiatric discourse on sexual deviance. In both understandings, the necessity of treatment remains consistent with the need for treatment of other psychiatric disorders. The way that treatment is carried out depends on whether the sex worker is identifiable as a victim. If they are, they are addressed through psychiatry. If the source of their pathology is not identifiable--if they cannot be fit into the narrative of victimhood ascribed to sex workers--or if they refuse psychiatric intervention, they are "treated" through their incorporation into the carceral state. This dichotomy--that of a sex worker who has fallen but can be saved versus the sex worker who is sexually deviant, and determined to remain so--harkens back to the narratives perpetuated in the early 19th century.

The deployment of this dichotomy is continually evinced state regulatory practices that are influenced by these pathological conceptualizations of sex workers--directly or indirectly. Carceral feminism's emphasis on sex workers as victims also operates in tandem with this pathological conceptualizations of sex work. The above policies and articles are significant in that they demonstrate 
several ways in which understandings of sex workers as pathological and carceral feminism reconfigure the legal regulation of sex workers, remaking sex work as a vehicle for the expansion of the carceral state.

\section{Conclusion:}

In this thesis I demonstrated that sex workers are pathologized and medicalized, and described how they are regulated within the U.S. legal and carceral system. I argued that the taking up of carceral feminist logics and rhetoric by the police has worked to expand carceral regulation of sex workers.

Understanding pathologization as the process through which something is made to be understood as psychologically abnormal or the product of psychological disorder, I demonstrated that sex work, as a form of sexual deviance, has been characterized as pathological in American psychiatric discourse. I described a history in which sex workers have been identified as the sources and carriers of diseases, even named a disease themselves. I defined medicalization as the process through which human issues are made to be medical issues, and subject to medical regulation as such. Medical regulation, in the case of sex workers, has manifested through the conflation of sex workers and venereal disease by medicine and the law--which has influenced the ways the sex workers are legally regulated.

I also addressed the legal regulation of sex workers in the United States, and situated them within the carceral state. In addition, I demonstrated that feminist logics and rhetoric have been taken up by the police and policy makers in order to expand the regulation of sex workers and the overall reach of the carceral state. This uptake is framed by the rise of neoliberal forms of governance, the carceral state, and carceral feminism--phenomena that are interconnected and have all operated to reconfigure the state's relationship to sex workers and its overall regulatory capacities. 
The relationship between sex workers and the state has been continuously shaped by the medicalization, pathologization, and legal regulation of sex workers. This relationship is not experienced in the same way by every sex worker. Sex workers continue to occupy a controversial place in contemporary politics, scholarship, public health discourse, feminist discourse, and bioethics--among other disciplines. That sex work has been made a vehicle for the expansion of the carceral state through the uptake of feminist rhetoric renders its study increasingly dynamic and urgent for those who are invested in the dismantling of the carceral state, the advancement of sex workers, and the protection of women and children from sexual violence.

\section{Works Cited:}

Alter, C. (2016.). Sex Buyers: Why Cops Across the U.S. Target Men Who Buy Prostitutes. Retrieved March 04, 2017, from http:/time.com/sex-buyers-why-cops-across-the-u-s-target-men-who-buy-prostitutes/ American Psychiatric Association. History of the DSM. Retrieved March 05, 2017, from https://www.psychiatry.org/psychiatrists/practice/dsm/history-of-the-dsm

Amin, A. (2005). Violence Against Sex Workers and HIV Prevention. WHO Global Coalition on Women and AIDS, (3), information bulletin series.

Bayer, R. (1987). Homosexuality and American psychiatry: the politics of diagnosis: with a new afterword on AIDS and homosexuality. Princeton, NJ: Princeton University Press.

Block, A. D., \& Adriaens, P. R. (2013). Pathologizing Sexual Deviance: A History. Journal of Sex Research, 50(3-4), 276-298. doi:10.1080/00224499.2012.738259 
Brown, E. N. (2014, June 04). Criminalizing Sex Work Clients: the Hot New Anti-Prostitution Strategy That Works About as Well as the Old Strategy. Retrieved March 04, 2017, from http://reason.com/blog/2014/06/04/criminalizing-sex-work-clients-study

Brown, W. (2015). Undoing the demos: neoliberalism's stealth revolution. New York, NY: MIT Press.

Bumiller, Kristin.In an Abusive State: How Neoliberalism Appropriated the Feminist Movement against Sexual Violence. Durham: Duke UP, 2008. Print.

Campaign, H. R. (n.d.). The Lies and Dangers of "Conversion Therapy". Retrieved March 05, 2017, from http://www.hrc.org/resources/the-lies-and-dangers-of-reparative-therapy

Curran, W. J. (1975). Venereal disease detention and treatment: Prostitution and civil rights. American Journal of Public Health, 65(2), 180-181. doi:10.2105/ajph.65.2.180

Davidson, Julia O'connell. "'Sleeping with the Enemy’? Some Problems with Feminist Abolitionist Calls to Penalise Those Who Buy Commercial Sex."Social Policy \& Society Social Policy and Society2.1 (2003): 55-63. Web

El-Bassel, N., Schilling, R. F., Irwin, K. L., Faruque, S., Gilbert, L., Bargen, J. V., . . . Edlin, B. R. (1997). Sex trading and psychological distress among women recruited from the streets of Harlem. American Journal of Public Health, 87(1), 66-70. doi:10.2105/ajph.87.1.66

Flaherty, J. (2015, April 18). Her Crime? Sex Work in New Orleans. Retrieved March 05, 2017, from http://www.colorlines.com/articles/her-crime-sex-work-new-orleans

George, A., Vindhya, U., \& Ray, S. (2010, April 24). Sex Trafficking and Sex Work: Definitions, Debates and Dynamics — A Review of Literature. Economic and Political Weekly, 45(17), 64-73. Retrieved August 23, 2016, from JSTOR. 
Gottschalk, M. (2011). The past, present, and future of mass incarceration in the United States. Criminology \& Public Policy, 10(3), 483-504. doi:10.1111/j.1745-9133.2011.00755.x

Gruskin, S., \& Ferguson, L. (2009). Government regulation of sex and sexuality: In their own words. Reproductive Health Matters, 17(34), 108-118. doi:10.1016/s09688080(09)34483-3

Harmon, L. (2014, May 31). To curb prostitution, concentrate on the Johns - The Boston Globe. Retrieved March 04, 2017, from http:/www.bostonglobe.com/opinion/2014/05/30/curb-prostitution-concentrate-johns/MZcgX TN3INN1jEg4A2Ow8K/story.html

Hernández, K. L., Muhammad, K. G., \& Thompson, H. A. (2015, June 01). Introduction: Constructing the Carceral State. Retrieved March 05, 2017, from https://academic.oup.com/jah/article/102/1/18/686730/Introduction-Constructing-the-CarceralState

Hobson, B. M. (1987). Uneasy Virtue:The Politics of Prostitution and the American Reform Tradition. New York: Basic Books, Inc.

Human Rights Watch. Sex Workers at Risk:Condoms as Evidence of Prostitution in Four US Cities . (2015, July 06). Retrieved March 4, 2017, from https:/www.hrw.org/report/2012/07/19/sex-workers-risk/condoms-evidence-prostitution-fourus-cities

Koster, K., \& Dunn, R. (n.d.). Mandatory HIV Testing and the Criminalization of HIV-Positive Sex Workers in the United States. Retrieved from http://www.swopusa.org/wpcontent/uploads/2015/10/Report-MandatoryHIVTestingandtheCriminalizationofHIV- 


\section{PositiveSexWorkersintheUnitedStates.pdf}

Landis, J. H. (1913). The Social Evil In Relation To The Health Problem. American Journal of Public Health, 3(10), 1073-1086. doi:10.2105/ajph.3.10.1073

Leigh, C. (1988). NO MANDATORY TESTING! A Feminist Prostitute Speaks Out by Carol Leigh. Retrieved November 3, 2016, from http:/www.ontheissuesmagazine.com/1988vol10/vol10_1988_3.php

Leonard, T. L., Freund, M., \& Platt, J. J. (1989). Behavior of clients of prostitutes. American Journal of Public Health, 79(9), 1309-1310. doi:10.2105/ajph.79.9.1309-b

Maher, J., Pickering, S., \& Gerard, A. (2012). Privileging Work Not Sex: Flexibility and Employment in the Sexual Services Industry. The Sociological Review, 60(4), 654-675. doi:10.1111/j.1467-954x.2012.02128.x

Mitchell, T. (1991). The Limits of the State: Beyond Statist Approaches and Their Critics. The American Political Science Review, 85(1), 77-97. doi:10.2307/1962879

Morgan, K. P. (1998). Contested Bodies, Contested Knowledges: Women, Health, and the Politics of Medicalization. In S. D. Sherwin (Ed.), The Politics of Women's Health: Exploring Agency and Autonomy (pp. 83-121). Temple University Press.

Murphy, W. (2014, June 04). 'Flush the Johns' defendants now can plead to reduced charge. Retrieved March 08, 2017, from http:/www.newsday.com/long-island/nassau/flush-the-johns-defendants-now-can-plead-to-red uced-charge-da-s-office-says-1.8333288?firstfree=yes

ProConOrg Headlines (2016). US Federal and State Prostitution Laws and Related Punishments.. http://prostitution.procon.org/view.resource.php?resourceID=000119. 
California Penal Code: Loiter With Intent to Commit Prostitution. (n.d.). Retrieved March 4, 2017, from http:/prostitutiondefenseattorney.com/penal-code-653-22-a-loitering-with-intent-to-commit-pc $-647 b . h t m l$

Roberts, R. (2014, May 10). Dear Johns: St. Louis police nab 9 for patronizing prostitution. Retrieved March 04, 2017, from http://fox2now.com/2014/05/09/dear-johns-st-louis-police-nab-9-for-patronizing-prostitution/

Rolfs, R. T., Goldberg, M., \& Sharrar, R. G. (1990). Risk factors for syphilis: Cocaine use and prostitution. American Journal of Public Health, 80(7), 853-857. doi:10.2105/ajph.80.7.853

Rosenberg, M. J., \& Weiner, J. M. (1988). Prostitutes and AIDS: A health department priority? American Journal of Public Health, 78(4), 418-423. doi:10.2105/ajph.78.4.418

Sadler, J. Z., Jotterand, F., Lee, S. C., \& Inrig, S. (2009). Can medicalization be good? Situating medicalization within bioethics. Theoretical Medicine and Bioethics, 30(6), 411-425. doi:10.1007/s11017-009-9122-4

Sanders, T., \& Campbell, R. (2007). Designing out vulnerability, building in respect: violence, safety and sex work policy. The British Journal of Sociology, 58(1), 1-19. doi:10.1111/j.1468-4446.2007.00136.x

Sanders, T., O'Neill, M., \& Pitcher, J. (2013). Prostitution: sex work, policy and politics. Los Angeles: Sage.

Schantz. (2006). Encyclopedia of Prostitution and Sex Work (Vol. 1). Westport, CT: Greenwood Publishing Group. 
Spongberg, M. (1997). Feminizing venereal disease: the body of the prostitute in nineteenth-century medical discourse. Washington Square, NY: New York University Press.

Weitzer, R. (2010). The Movement to Criminalize Sex Work in the United States. Journal of Law and Society, 37(1), 61-84. doi:10.1111/j.1467-6478.2010.00495.x

Whitford E. (2017). NYPD Still Arresting Sex Workers Despite Pledge To Target Traffickers. Retrieved March 4, 2017, from http:/gothamist.com/2017/02/24/nypd_sex_trafficking_immigrants.php

Wurth, M. H., Schleifer, R., Mclemore, M., Todrys, K. W., \& Amon, J. J. (2013). Condoms as evidence of prostitution in the United States and the criminalization of sex work. Journal of the International AIDS Society, 16(1). doi:10.7448/ias.16.1.18626 